\title{
Fine Needle Aspiration Cytology of Cervical Lymph Nodes: Our Experience
}

\author{
Aditi Dholakia $^{1}$, Dimple Darad ${ }^{1 *}$ and Dharmesh Vasavada ${ }^{2}$ \\ ${ }^{1}$ Dept of General Pathology, Gotri Medical College \& Hospital, Vadodara, Gujarat, India \\ ${ }^{2}$ Dept of Oral Pathology, M P Dental College \& Hospital \& Oral Research Institute, Vadodara, Gujarat,India
}

\section{ABSTRACT}

Background: Fine Needle Aspiration Cytology (FNAC) is simple, quick, inexpensive and minimally invasive technique used to diagnose different types of swellings located in the head and neck.

Methods: A prospective study was performed in a tertiary health care centre from January 2016 to September 2016 in Vadodara, Gujarat. Fine Needle Aspiration Diagnosis was correlated with detail of relevant clinical findings and investigation.

Results: In this study, total of 260 cases of suspected cervical lymphadneopathy were subjected to cytological evaluation. The lesions cases were broadly categorised as inflammatory lesions, cystic lesions, benign tumor \& tumor like conditions, salivary gland lesions and malignant lesions. Out of these 260 cases, 184 cases were given the diagnosis of either inflammatory or benign conditions and rest 76 cases were diagnosed positive for malignancy. Out of 76 cases positive for malignancy, 65 cases gave the diagnosis of Squamous cell carcinoma metastasing to lymphnode.

Conclusion: Fine Needle Aspiration Cytology is easy, simple, safe and non invasive procedure for diagnosis of head and neck swelling and easy way for surgeon whether to decide surgery or not.

Keywords: Head and Neck Swellings, Fine Needle Aspiration Cytology

\section{Introduction}

Fine needle aspiration cytology is routinely being used for the diagnosis of various neoplastic and non neoplastic lesions of head and neck region. ${ }^{1}$ It is a valuable procedure for the initial evaluation of swelling in head and neck region and it can easily differentiate between benign and malignant lesion. ${ }^{[1]}$

The use of fine needle aspiration cytology (FNAC) for the diagnosis of metastatic malignancies in the lymphnodes is an established method as lymphadenopathy may be the first sign of malignancy in a patient. ${ }^{[2]}$

FNAC not only confirms the presence of metastatic disease, but also gives clues regarding the nature and origin of the primary tumor. ${ }^{[3]}$ Moreover, the procedure is very cost effective, simple and free of complication, well tolerated by the patient on OPD basis and repeatable. ${ }^{[4]}$ It almost offers an accurate diagnosis for reactive lymphoid hyperplasia, infectious disease, granulomatous lymphadenitis, and metastatic malignancy. ${ }^{[5]}$ FNAC can avoid the need for excisional biopsy in most cases and allow rapid onset of therapy ${ }^{[6]}$

Masses in the head and neck are especially good targets for needle aspiration because many are superficially located or otherwise accessible to puncture. ${ }^{[7]}$ Head and
Neck sites account for approximately one half of all body sites aspirated. The largest numbers of aspirates are from cervical lymph node enlargements, metastatic squamous carcinoma being the most common lesion encountered. ${ }^{[7]}$

The prime objective of study was to assess the diagnostic accuracy of FNAC in the Head and Neck tumors, to assist the surgeon in selection of the patient for surgery and palliative therapy and to help the surgeon in detecting the metastasis and staging of the certain tumors.

\section{Materials and Methods}

The study was performed in a tertiary health care centre from January 2016 to September 2016 in Vadodara, Gujarat after obtaining the necessary permission for the same. Patients referred to the Dept of Pathology with the chief complaint of swelling in head and neck region and who required FNAC procedure as a primary investigation were considered for the study. The procedure was explained to the patient in the language he/she understood and written consent was obtained from the patient. Detailed personal and medical history was taken for all the patients in the Performa prepared.

For taking FNA supine position was preferred. All the FNAC were performed using a 23-gauge needle after 
sterilizing the part with alcoholic disinfectant. An average of 2 passes was performed and minimum 5 slides were prepared. Two slides were air dried and stained by Giemsa stain and the remaining 3 slides were fixed in alcohol and stained with $\mathrm{H} \& \mathrm{E}$ stain. The FNA results were reviewed and the morphology of the individual cells and their patterns in the smears were studied in detail. In this study the FNAC diagnosis were correlated with the histological findings, wherever available, or the clinical correlation was obtained.

\section{Result}

During the period of one year, a total of 550 of FNACs from various sites were performed. Out of these 260 aspirates were obtained from suspected enlarged lymph nodes in the head and neck region. All the haematological malignancy was excluded.

Out of 260 patients, 101 patients were female and 159 male patients. Out of these 159 male patients 82 patients and out of 101 female patients 2 patients were addicted to some form of tobacco.(Table 1)

Out of these 82 tobacco abusers with cervical lymphnode enlargement under investigation, 58 patients were diagnosed as metastatic squamous cell carcinoma, 2 patients diagnosed as metastatic epithelial malignancy with nueroendocrine differentiation; 11 patients were having metastatic epithelial malignancy and remaining 12 patients were negative for malignancy were given the cytological diagnosis of inflammatory condition. Two female patients were diagnosed as metastasis of squamous cell carcinoma.

Out of total 78 cases of malignant lesions, histological correlation was possible in 50 cases. In all the 50 cases were positive for malignancy in histological examination also; thus making FNAC 100\% sensitive for detection of malignancy.

Table 1: Distribution of Various Head \& Neck Pathologies

\begin{tabular}{|c|c|c|c|c|}
\hline \multirow[t]{2}{*}{ Benign Conditions } & \multicolumn{2}{|c|}{ Female Patients } & \multicolumn{2}{|c|}{ Male Patients } \\
\hline & Non Tobacco Users & Tobacco Users & Non Tobacco Users & Tobacco Users \\
\hline \multicolumn{5}{|l|}{ Inflammation: } \\
\hline Acute Suppuative Inflammation & 4 & & 7 & 2 \\
\hline Reactive Lymphadenopathy & 21 & & 13 & 4 \\
\hline Granulomatous & 46 & & 29 & 10 \\
\hline Saliadenitis & 3 & & 2 & 1 \\
\hline Fungal Infection & 1 & & 1 & 0 \\
\hline \multicolumn{5}{|l|}{ Benign Tumor And Tumor Like Conditions } \\
\hline Benign Cystic Leison Of Salivary Gland & 2 & & 4 & 0 \\
\hline Branchial Cyst & 2 & & 3 & 0 \\
\hline Keratinous Cyst & 4 & & 4 & 0 \\
\hline Thyroglossal Cyst & 3 & & 2 & 0 \\
\hline Ectopic Thyroid Tissue & & & 1 & 0 \\
\hline Lipoma & 2 & & 2 & \\
\hline Benign spindle cell tumor & & & 1 & \\
\hline \multicolumn{5}{|l|}{ Benign Salviary Gland Tumor } \\
\hline Pleomorphic Adenoma & 4 & & 1 & 1 \\
\hline Warthins Tumor & 0 & & 0 & 2 \\
\hline \multirow[t]{2}{*}{ Basal Cell Adenoma } & 0 & & 1 & 0 \\
\hline & 93 & & 71 & 20 \\
\hline \multicolumn{5}{|l|}{ Malignant Conditions } \\
\hline Squamous Cell Carcinoma & 5 & 2 & 2 & 56 \\
\hline Adenocarcinoma & 1 & & 0 & \\
\hline Neuroendocrine Differetiation & 0 & & 0 & 3 \\
\hline Metastatic Epithelail Malignancy & 3 & & 1 & 3 \\
\hline
\end{tabular}




\begin{tabular}{|l|c|c|c|c|}
\hline Benign Conditions & \multicolumn{2}{|c|}{ Female Patients } & \multicolumn{2}{c|}{ Male Patients } \\
\hline & Non Tobacco Users & Tobacco Users & Non Tobacco Users & Tobacco Users \\
\hline $\begin{array}{l}\text { Malignant soft tissue tumor- } \\
\text { Rhabdomyosarcoma }\end{array}$ & & & 1 & \\
\hline Malignant Salivary Gland Tumor & & & & \\
\hline Acinic Cell Carcinoma & 0 & & 1 & 0 \\
\hline Mucoepidermoid Carcinoma & 0 & & 7 & 0 \\
\hline & 99 & 2 & 72 \\
\hline
\end{tabular}

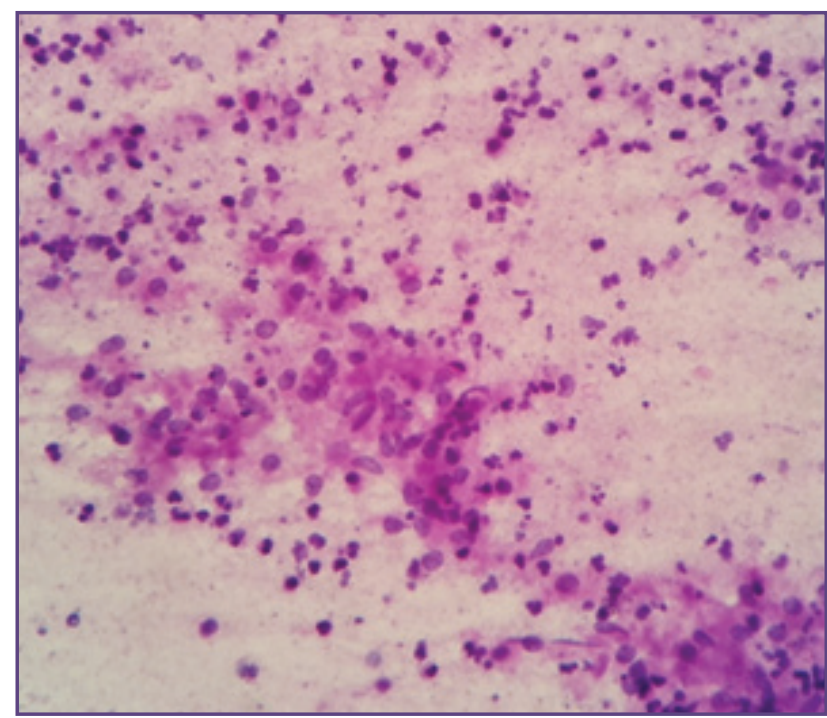

Fig. 1: Granuloma formation in the background of acute on chronic inflammation. (10X).

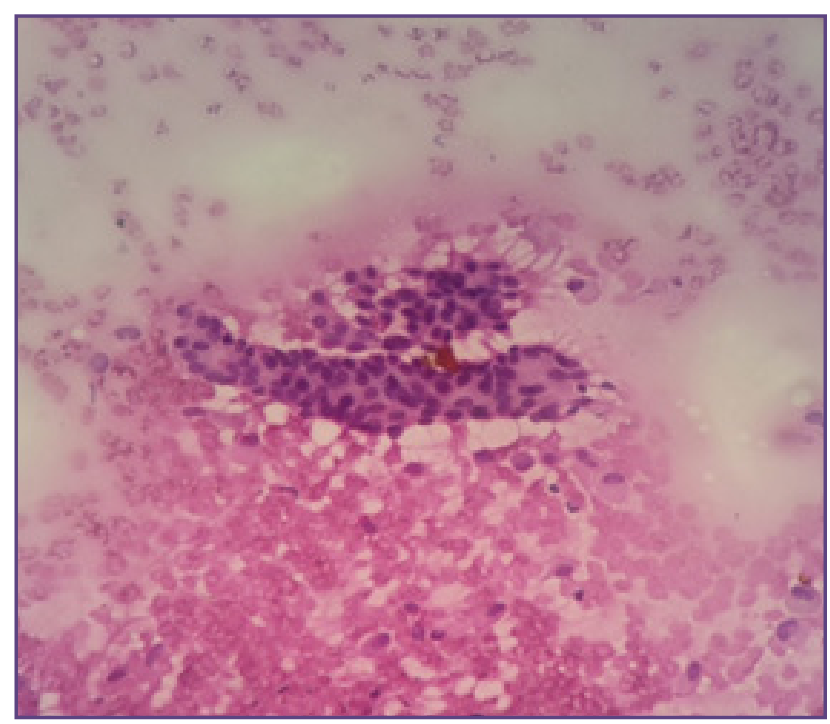

Fig. 3: A papillally arrangement of thyroid follicular cells in the lymphoid background. An aspirate from cervical lymphnode - metastasis of papillary carcinoma of thyroid. (10X).

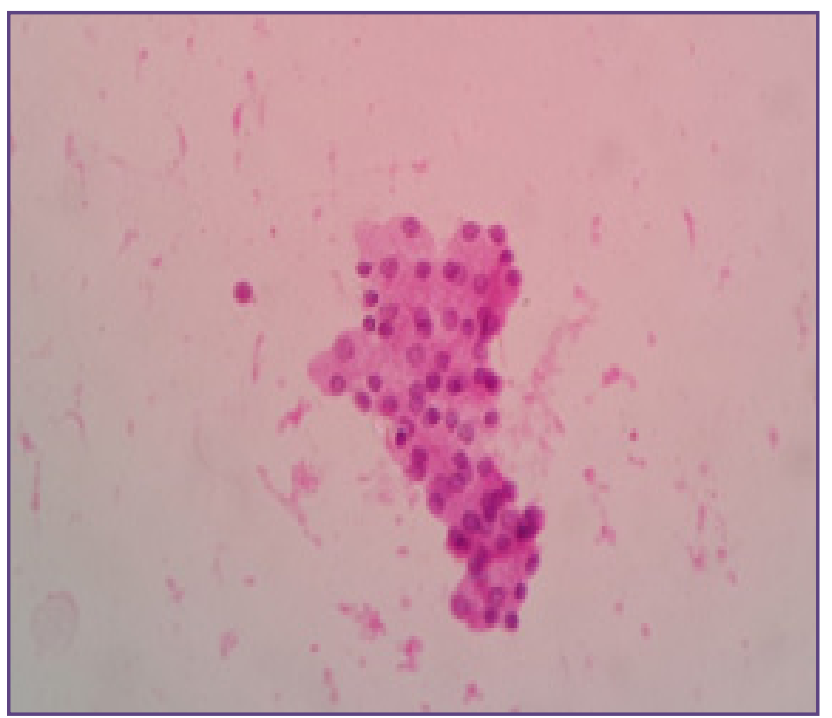

Fig. 2: cluster of malignant salivary epithelial cells- having small, monomorphic nuclei, arranged in acinar pattern. An aspirate from a nasal mass (10X).

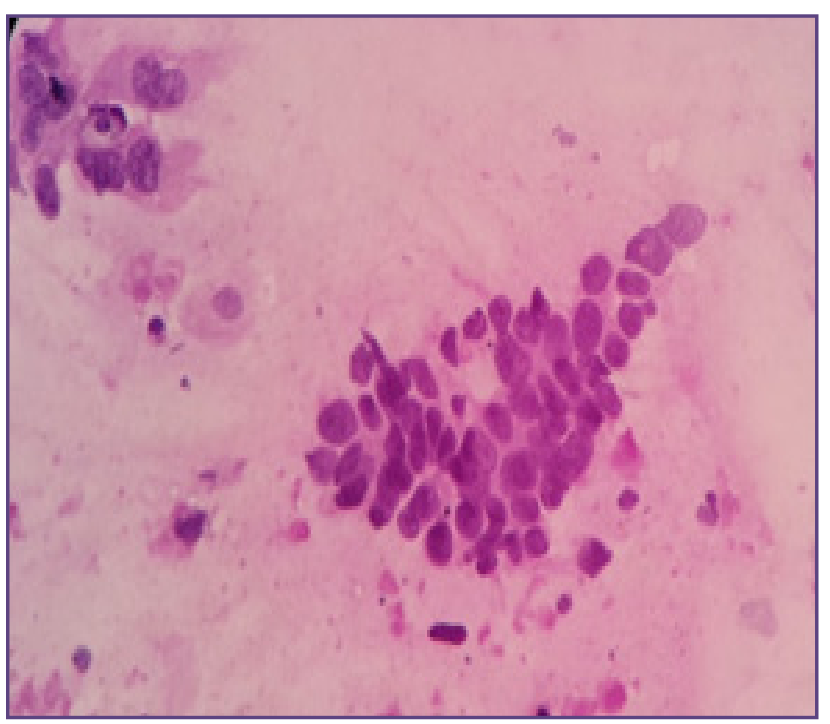

Fig. 4: A Cluster of moderately differentiated malignant squamous cells along with few dysplastic sqamous cells in the background (40X). 


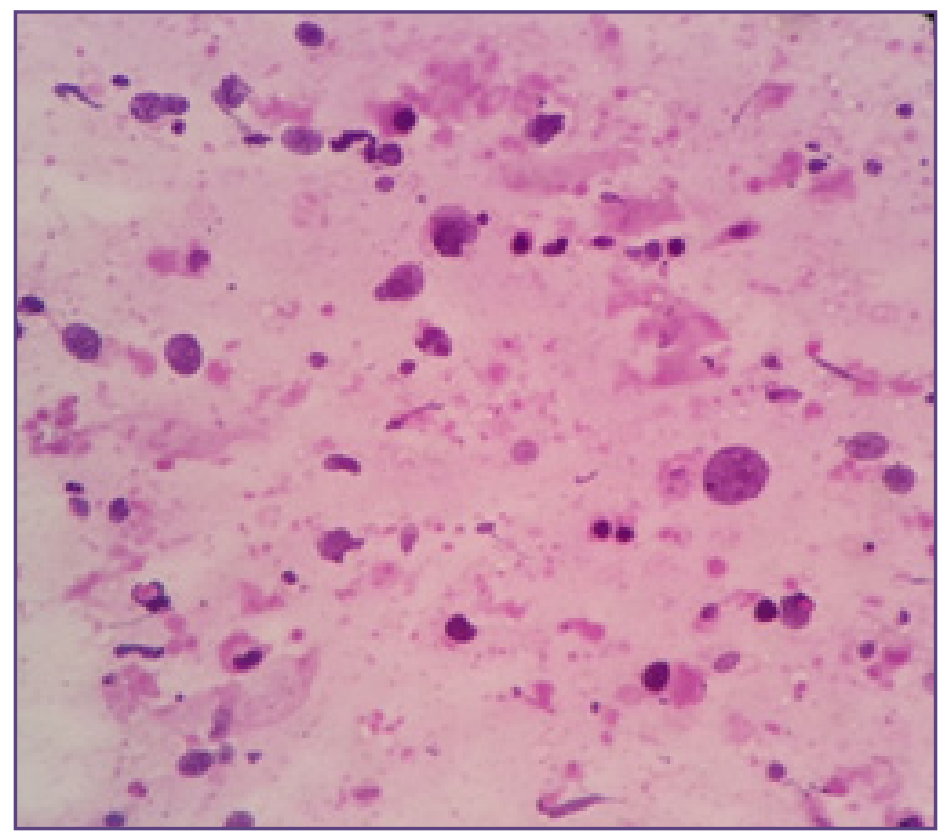

Fig. 5: Scattered highly pleomorphic malignant epithelial cells in lymphoid background- Metastasis from epithelial malignancy to the cervical lymphnode (10X).

\section{Discussion}

Enlarged lymph nodes in head and neck region are most common indication for FNAC. ${ }^{[8]}$ Over the years, FNAC has been found to be very useful, simple, cost effective and accurate in work up of various neoplastic \& non neoplastic lesions, especially in head neck region. ${ }^{[1]}$ Lymph nodes that are clinically suspicious for metastasis are the most common indications for FNAC. ${ }^{[9]}$ FNAC has a significantly no risk of any subsequent complications. Except for minimal bleeding and some pain at the aspiration, FNA is an uneventful procedure. FNAC is having a high diagnostic rate to differentiate benign and malignant lesions. It is particularly useful for confirming metastasis of a known malignant disease or recurrence of already cured malignancy. ${ }^{[10]}$

In this study, total of 260 cases of suspected cervical lymphadneopathy were subjected to cytological evaluation. The cases with insufficient material were not taken in the consideration. All the haematological malignancies \& Thyroid lesions are not included in the present study.

All the 260 cases were broadly categorised as inflammatory lesions, cystic lesions, benign tumor \& tumor like conditions, salivary gland lesions and malignant lesions.

Among these 260 patients, 101 patients were female and 159 patients were male. Out of total 260 patients, 82 male patients had given the history of tobacco addiction and only 2 female patients were having positive history of tobacco abuse.
Out of these 260 cases, 184 cases were given the diagnosis of either inflammatory or benign conditions and rest 76 cases were diagnosed positive for malignancy. Among the benign conditions, most frequent pathology presented as cervical lymphadenopathy was Chronic granulomatous inflammation- Tuberculosis. ${ }^{[7,11]}$ Gupta AK reported the lymph node involvement of cervical site $(62 \%)$, supraclavicular $(16 \%)$ and others $(22 \%)$. Present study revealed that cervical lymph node was commonest site of involvement.

Out of 76 cases positive for malignancy, 65 cases gave the diagnosis of Squamous cell carcinoma metastasing to lymphnode, making it most frequent malignancy presenting as cervical lymphadenopathy.

Out of these 65 cases of squamous cell carcinoma, 58 male and 2 female patients gave the history of some form of tobacco abuse. This confirms strong association between tobacco abuse and squamous cell carcinoma.

In the present study, total of 260 cases were further categorised in different age groups and frequency of occurrence of Tuberculosis and malignant conditions were assessed. That showed the peak incidence of tuberculosis is seen in $2^{\text {nd }}$ and $3^{\text {rd }}$ decades of life; and incidence of malignancy shows its peak in $5^{\text {th }}$ and $6^{\text {th }}$ decades. The incidence of malignancy rose through the age group to greater than $85 \%$ in patients above the age of 60 years. Hence there is a pressing need for FNAC of enlarged lymphnodes in head \& neck region in elderly age groups. 
Only one case of malignancy which falls in paediatric age group was actually of embryonal Rhabdomyosarcoma, which is a paediatric malignancy and commonly occurs in $1^{\text {st }}$ and $2^{\text {nd }}$ decades of life.

Out of total 260 cases, histological correlation was available in 97 cases. Among the malignant lesions, histological correlation was possible in 50 cases in the present study.

One very important aid in working up the neck mass and head and neck oncology in general is the looking at the neck level of involvement. For example, cancers of oral cavity will involve level 1 nodes (node in the submandibular and submental triangles of neck); where as metastases from nasolaryngeal region involves level 2 nodes (nodes along the upper one third of the sternocleidomastoid muscle) more commonly.

\section{Conclusion}

FNAC is very useful for pre-operative diagnosis of lymph node, thyroid gland, salivary gland, orbit and other swellings in head and neck region, and thus helps surgeon in selecting the patient for palliative or surgical management. In the present study also FNAC of head and neck proved to be a useful tool in diagnosis.

\section{Reference}

1. Khan N, Afroz N, Haider A, Hassan MJ, Hashmi SH, Hasan SA. Role of fine needle aspiration, imprint and scrape cytology in the evaluation of intraoral lesions. Journal of cytology/ Indian Academy of Cytologists. 2013; 30(4):263-269.

2. Ghartimagar, Ghosh, Ranabhat, Shrestha M, Narasimhan, Talwar Utility of fine needle aspiration cytology in metastatic lymph nodes. Journal of Pathology of Nepal 2012;1:92-95.
3. Modi P, Oza H, Bhalodia J. Utility and Adequacy of Fine Needle Aspiration Cytology in Head and Neck Lesions: A Hospital Based Study. Int J Sci Stud 2014;2(8):100-105.

4. Pandey P, Dixit A, Mahajan N C. The diagnostic value of FNAC in assessment of superficial palpable lymph nodes: a study of 395 cases Al Am een J Med Sci 2013; 6(4):320-327.

5. Nesreen H, Neveen S Reliability of fine needle aspiration cytology (FNAC) as a diagnostic tool in cases of cervical lymphadenopathy. Journal of the Egyptian National Cancer Institute 2011; 23: 105-114.

6. Howlett DC, Harper B, Quante M, Berresford A, Morley M, Grant J. Diagnostic adequacy and accuracy of fine needle aspiration cytology in neck lump assessment: results from a regional cancer network over a one year period. J Laryngol Otol 2007;121(6):571-9

7. Solanki P, Patel A, Taviad P, Chaudhari V, Patel S Fine Needle Aspiration Cytology As A Diagnostic Procedure In Head And Neck Swellings. National Journal of Community Medicine 2012; 3(3):433-436.

8. Steel BL, Schwart MR, Ramzy I. Fine needle aspiration biopsy in the diagnosis of lymphadenopathy in 1103 patients. Role, limitations and analysis of diagnostic pitfalls. Acta Cytol. 1995;39(1):76-81.

9. Bagwan I, Kane S, Chinoy R. Cytologic Evaluation of the Enlarged Neck Node: FNAC Utility in Metastatic Neck Disease. The Internet Journal of Pathology 2006; 6(2):1-7.

10. Singal P, Bal MS, Kharbanda J, Sethi PS. Efficacy of fine needle aspiration cytology in Head and Neck lesions. Int J Med and Dent Sci 2014; 3(2):421-430.

11. Sumit M, Suchandra R, Pradip MK. Fine needle aspiration cytology of supraclavicular lymph nodes: Our experience over a three-year period. Journal of Cytology 2011; 28 (3):108-110.

*Corresponding author:

Dr Dimple Darad, Associate Professor, Dept of General Pathology, Gotri Medical College \& Hospital, Vadodara, Gujarat, India

Email: dimpledarad@yahoo.com

Date of Submission : 08.12.2016

Date of Acceptance : 17.05.2017

Financial or other Competing Interests: None.

Date of Publication : 31.08.2017 